\title{
Pyrrolizidine alkaloids in honey: Quantification with and without standards
}

Wang, Tingting; Frandsen, Henrik Lauritz; Roed Christiansson, Natasha ; Rosendal, Sofie Elisabeth; Pedersen, Mikael; Smedsgaard, Jørn

Published in:
Food Control

Link to article, DOI:

10.1016/j.foodcont.2018.11.033

Publication date:

2019

Document Version

Peer reviewed version

Link back to DTU Orbit

Citation $(A P A)$ :

Wang, T., Frandsen, H. L., Roed Christiansson, N., Rosendal, S. E., Pedersen, M., \& Smedsgaard, J. (2019). Pyrrolizidine alkaloids in honey: Quantification with and without standards. Food Control, 98, 227-237. https://doi.org/10.1016/j.foodcont.2018.11.033

\section{General rights}

Copyright and moral rights for the publications made accessible in the public portal are retained by the authors and/or other copyright owners and it is a condition of accessing publications that users recognise and abide by the legal requirements associated with these rights.

- Users may download and print one copy of any publication from the public portal for the purpose of private study or research.

- You may not further distribute the material or use it for any profit-making activity or commercial gain

- You may freely distribute the URL identifying the publication in the public portal 


\section{Accepted Manuscript}

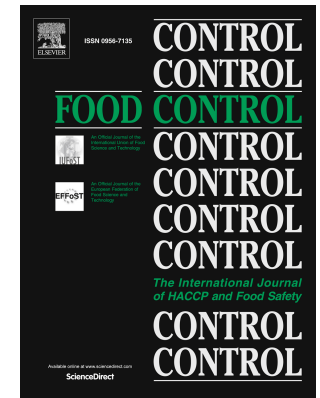

Pyrrolizidine alkaloids in honey: Quantification with and without standards

Tingting Wang, Henrik Lauritz Frandsen, Natasha Roed Christiansson, Sofie Elisabeth Rosendal, Mikael Pedersen, Jørn Smedsgaard CONTROL

PII: S0956-7135(18)30578-4

DOI: https://doi.org/10.1016/j.foodcont.2018.11.033

Reference: JFCO 6402

To appear in: Food Control

Received Date: 17 August 2018

Revised Date: 19 October 2018

Accepted Date: 12 November 2018

Please cite this article as: Wang T., Frandsen H.L., Christiansson N.R., Rosendal S.E., Pedersen M. \& Smedsgaard Jø., Pyrrolizidine alkaloids in honey: Quantification with and without standards, Food Control (2018), doi: https://doi.org/10.1016/j.foodcont.2018.11.033.

This is a PDF file of an unedited manuscript that has been accepted for publication. As a service to our customers we are providing this early version of the manuscript. The manuscript will undergo copyediting, typesetting, and review of the resulting proof before it is published in its final form. Please note that during the production process errors may be discovered which could affect the content, and all legal disclaimers that apply to the journal pertain. 


\section{Pyrrolizidine alkaloids in honey: Quantification with and}

\section{without standards}

3

$4 \quad$ Tingting Wang, Henrik Lauritz Frandsen, Natasha Roed Christiansson, Sofie Elisabeth

National Food Institute, Division of Analytical Food Chemistry, Technical University of Denmark,

7 Kemitorvet Building 202, DK 2800 Lyngby, Denmark

8

9

10

11

12

13

14

15

16

17

18

$19 *$ Corresponding author: Jørn Smedsgaard

20 E-mail address: smeds@ food.dtu.dk 


\section{ABSTRACT}

22 Quantification of a large number of compounds in the absence of authentic standards is always a 23 challenge. More than 600 pyrrolizidine alkaloids (PAs) have been found in plants however only limited 24 number of PAs standards are commercially available. As PAs are the most widely distributed natural 25 plant toxins with threat to human health, risk assessment calls for quantitative analytical methods with 26 a wide scope including PAs without available standards. In this study, a method was developed that 27 allows simultaneous quantification of 12 PAs in the honey samples by using HPLC-HRMS with 28 authentic standards. This method was further extended to screen for other potential PAs in the honey 29 using multi-target screening combined with a quantitative prediction model in the cases that authentic 30 PAs were not available. The prediction model was subsequently validated by cross-validation and 31 additional PAs standards which were not included in the model. The maximum concentration 32 prediction error was $50.8 \%$.

37 KEY WORDS: Pyrrolizidine alkaloids; validation; quantification without standards; screening; honey; HPLC-HRMS 


\section{INTRODUCTION}

41 Pyrrolizidine alkaloids (PAs) are a group of at least 600 different secondary metabolites that are

42 produced by more than 6000 plant species worldwide. They are suspected to be hepatotoxic and genotoxic carcinogens in humans, since these PAs are activated to electrophilic compounds through the liver's metabolic enzymes (Bolechová, Čáslavský, Pospíchalová, \& Kosubová, 2015: Lucchetti et al., 2016). Single or continuous intake of 1, 2-unsaturated PAs can cause hemorrhagic necrosis and hepatic venous occlusion, and also increase the incidence of liver haemangiosarcoma for chronic risk assessment (EFSA, 2017). As approximately 3\% of all flowering plants contain PAs compounds (Boppré, 2011), this PAs exposure occurs worldwide, and intoxication by contaminated herbal teas, cereals, herbal medicine, salads, and feed, have been reported (Culvenor, Edgar, Smith, Kumana, \& Lin, 1986; Molyneux, Gardner, Colegate, \& Edgar, 2011; Tandon, Tandon, \& Narndranathan, 1976; Wiedenfeld, 2011). Honey is one of the food products that contain PAs. Bees collect pollen or floral nectar from a wide variety of plants and therefore diverse profiles of PAs are observed in honey (Boppré, Colegate, \& Edgar, 2005; Lucchetti et al., 2016). Previous studies have shown a very high frequency of PA positive honey samples, e.g., up to $94.2 \%$ samples contain PAs in a study of Spanish raw honey $(\mathrm{n}=103)$ (Martinello, Cristofoli, Gallina, \& Mutinelli, 2014; Orantes-Bermejo, Serra Bonvehí, Gómez-Pajuelo, Megías, \& Torres, 2013). Hence with regard to the increased awareness of this potential health concern, it is important to clarify the types and concentration of PAs in honey.

Based on the data collected by the European Food Safety Authority (EFSA), a total of 64 PAs were reported in food products (EFSA, 2011), while the lack of certified standards hampers an unequivocal quantification. This is, particularly, a problem in PA analysis, where a complex and variable profile of 
61 PAs can be expected. To date, very limited PA are commercially available and no more than approximately 34 different PAs in one method are reported, while isotopic labeling PAs are still not commercially available (Schenk, Siewert, Toff, 2017). This is unlikely to change in the near future since there is no facile chemical access, in vitro biosynthesis and isolation (EFSA, 2011). Therefore measuring the concentrations of a wide variety of PAs within a single experimental detection continues to remain challenging. Many studies about semi-quantification model have been reported, and the ionization efficiency were reported to be correlated to $\mathrm{pKa}, \log \mathrm{P}$, molecular volume, molecular size, surface tension, or the WAPS value as developed by Kruve's group, (Alymatiri, Kouskoura, \& Markopoulou, 2015; Hermans, Ongay, Markov, \& Bischoff, 2017; Golubović, Birkemeyer, Protić, \& Otašević, 2016; Raji, et al., 2010; Oss, Kruve, Herodes, \& Leito, 2010; Kruve \& Kaupmees, 2017). However, their models either used for specific compounds (such as amino acid, steroids, peptides and sartans) or challenged to calculate the relevant descriptors used in the model. To our knowledge, there are still no quantitative prediction model developed specific for PAs up to now.

Solid-phase extraction (SPE), followed by HPLC-MS analysis is a commonly used sequence to analyze PAs in honey. However, the recovery of PAs from the samples are highly dependent on the types of cartridges, sample loading amount, and elutes used during the extraction procedures (Betteridge, Cao, \& Colegate, 2005; Bodi et al., 2014; Chung \& Lam, 2018; Colegate, Edgar, Knill, \& Lee, 2005). The determination and quantification are generally carried out by a target analysis using GC-MS (with and without derivatization), HPLC-MS or HPLC(GC)-MS/MS (Crews, Berthiller, \& Krska, 2010; Lucchetti et al., 2016; Molyneux et al., 2011). Latest LC-MS methods mostly relied on the high selectivity of mass spectrometry operated in the multiple reaction-monitoring (MRM) mode (Chung \& Lam, 2018; Kowalczyk \& Kwiatek, 2018), where the MRM method can only detect 
preselected PAs within the correct retention time windows and fragmentation patterns (These, Bodi, Ronczka, Lahrssen-wiederholt, \& Preiss-weigert, 2013). Furthermore, the PAs not included in the specific methods, e.g. if authentic standards are not available, will remain undetected and therefore not be quantified.

A screening approach (multi-target screening) using high resolution / accurate LC-QTOF-MS with full scan acquisition can achieve both high sensitivity and selectivity. Full-scan MS offer the advantage to determine a virtually unlimited number of analytes simultaneously without preselection of precursor ions. The screening approach also allows a retrospective "targeted" evaluation of data by reconstructing any desired ion chromatogram to explore the data for presence of additional PAs (Heeft, Bolck, Beumer, Nijrolder, Stolker, \& Nielen, 2009). These data are however qualitative in character as standards with known concentration is needed to determine the concentration of compounds.

The objective of this study is to develop a high-resolution analytical method to detect and estimate the concentrations of a wide range of PAs in honey, even for those without authentic PAs standards. Firstly, we developed a validated method that allows the simultaneous detection and quantification of 12 PAs in honey using HPLC-QTOF-MS with pure authentic standards. Secondly, the extracts of different honey samples were analyzed for occurrence of other PAs using a multi-target screening approach. Suspicious signals were verified by recording of product ions using a broadband fragmentation. Consequently, we proposed a semi-quantification strategy for those detected peaks without available standards through a quantitative prediction model (QPM). To evaluate this prediction model, feasibility and reliability have been validated by leave-one-out (LOO) cross validation. In addition, as a test, quantification of four unknown PAs, that were not included in the original dataset, 
has also been carried out. Finally, we estimated the contents of PAs in honey samples combining the available reference standards and the QPM.

\section{MATERIALS AND METHODS}

\subsection{Chemicals and reagents}

Milli-Q grade water was used for all analyses (Millipore Corporation, Molsheim, France). Methanol (LC-MS grade), acetonitrile (LC-MS grade), ammonium hydroxide solution (LC-MS grade), and formic acid (LC-MS grade) were purchased from Fluka (Steinheim, Germany). Pyrrolizidine alkaloids (PAs) (7-acetylintermedine, echimidine, heliotrine, heliotrine $N$-oxide, intermedine, intermedine $N$ oxide, lasiocarpine, lasiocarpine $\mathrm{N}$-oxide, lycopsamine, lycopsamine $\mathrm{N}$-oxide, retrorsine, retrorsine $\mathrm{N}$ oxide, senecionine, senecionine $N$-oxide, seneciphylline, seneciphylline $N$-oxide) were purchased from PhytoLab (PhytoLab GmbH \& Co. KG, Vestenbergsgreuth, Germany). Sulfuric acid (analytical grade, 95-97\%) was obtained from Merck (Darmstadt, Germany). All other solvents used in this study were of analytical grade.

Each alkaloid standard was dissolved in either acetonitrile or acetonitrile/water $(50 / 50 \mathrm{v} / \mathrm{v})$ depending on their solubility to obtain stock solutions at a concentration of $0.5 \mathrm{mg} / \mathrm{mL}$. All the stock solutions were stored at $-20^{\circ} \mathrm{C}$. Stock standard mixtures $(1 \mu \mathrm{g} / \mathrm{mL})$ were prepared in acetonitrile/water $(50 / 50 \mathrm{v} / \mathrm{v})$ from the individual stock solutions, and used set up calibration curves.

\subsection{Samples}

Thirty-two honey samples were included in this study purchased from either local supermarkets or bee keepers, originating from at least 10 different countries. The honey samples were declared to be collected from summer flowers, white clover, wild flowers, creamy flowers, heather flowers, acacia, 
fruit trees (apple, plum, rape), and etc. The information of samples: names, geographical and botanical origin, and symbols are listed in Table 1.

\subsection{Negative control and quality control samples}

Honey sample previously analyzed and found not containing PA compounds, was used as blank sample (mountain honey coming from wild flowers of Nicaragua) for method validation. Quality control (QC) samples were made by spiking blank honey samples $(25 \mu \mathrm{L}$ stock standard mixtures to $1.0 \mathrm{~g}$ blank honey sample). QC samples were analyzed in each series of samples and were controlled to be in the range of $\pm 20 \%$ of the validation results. If not, the whole set of samples were reanalyzed.

\subsection{Solid Phase extraction}

The strong cation exchange (SCX) SPE was found to be suitable for plant extracts and for a series of pyrrolizidine alkaloid/N-oxide (PAs/PANOs) representing the major hepatotoxic structural groups (monoesters, diesters and macrocyclic diesters of retronecine, heliotridine and otonecine bases), and also provided efficient capture from honey-based matrices and subsequent release into ammoniated methanol (Betteridge et al., 2005; Colegate et al., 2005). The SPE columns (150 mg/6 mL, Biotage Evolute Express CX) used in our study combines non-polar and SCX functionality for extraction of basic analytes from aqueous samples through a dual, mixed-mode mechanism. Also these specific SPE columns can be used without a preanalysis conditioning and equilibration steps without affecting the recovery significantly.

The extraction of PAs was based on a modified method from German Federal Institute of Risk Assessment (BfR) (BfR, 2013). One gram of honey was weighed into a $10 \mathrm{ml}$ centrifuge tube and dissolved in $3 \mathrm{~mL}$ of $0.05 \mathrm{M} \mathrm{H}_{2} \mathrm{SO}_{4}$ in water at room temperature by shaking for $30 \mathrm{~min}$. The samples were centrifuged at $2000 \times \mathrm{g}$ for $10 \mathrm{~min}$ at room temperature. The supernatant was transferred to a SPE 
cartridge by using a vacuum manifold. After loading the sample, the column was washed with $4 \mathrm{~mL}$ of $0.05 \mathrm{M} \mathrm{H}_{2} \mathrm{SO}_{4}$ followed by $4 \mathrm{~mL}$ of methanol, then the column was eluted with $5 \mathrm{~mL}$ of $2.5 \%(\mathrm{v} / \mathrm{v})$ ammonium hydroxide in methanol at a rate of $0.5-1 \mathrm{~mL} / \mathrm{min}$. The eluate was dried under a stream of nitrogen at $45^{\circ} \mathrm{C}$. The residue was dissolved in $0.5 \mathrm{~mL}$ acetonitrile/water $(5 / 95, \mathrm{v} / \mathrm{v})$, transferred to an Eppendorf vial, and centrifuged at $10.000 \times \mathrm{g}$ for $10 \mathrm{~min}$ at room temperature. Then $200 \mu \mathrm{L}$ of supernatant was transferred into a HPLC-vial with insert.

\subsection{HPLC-ESI-QTOF-MS.}

Samples were analyzed on an Agilent 1200 HPLC (Agilent Technologies, CA, U.S.) coupled to a Bruker Daltonics micro-TOFq mass spectrometer (Bruker Daltonics, Bremen, Germany). The resolution of the Bruker micro-TOFq is approximately 10000. Samples were injected onto a Nucleoshell C18 reversed-phase column $(2.7 \mu \mathrm{m}, 100 \times 2 \mathrm{~mm}$, MACHEREY-NAGEL GmbH \& Co. KG, Düren, Germany). The mobile phase consisted of water (A) containing $0.1 \%$ formic acid and 2.5 $\mathrm{mM}$ ammonium hydroxide, and acetonitrile (B). The analysis was done using a gradient elution at a flow rate of $0.3 \mathrm{~mL} / \mathrm{min}$ at $40{ }^{\circ} \mathrm{C}$ using the gradient: isocratic at $2 \%$ of $\mathrm{B}$ for $1.0 \mathrm{~min}$, then increased to $10 \%$ of B at $4.0 \mathrm{~min}$, to $40 \%$ of B at 9 min, and finally to $95 \%$ of B at 10.0 min and maintained to 11 min, where after the gradient returned to starting conditions $2 \%$ of B at $11.2 \mathrm{~min}$ followed by $3.8 \mathrm{~min}$ equilibration with $2 \%$ of $\mathrm{B}$ to giving a total runtime of $15 \mathrm{~min}$.

An electrospray ion source (ESI) was used in positive ion mode $\left(\mathrm{ESI}^{+}\right)$with the following settings: capillary voltage $4 \mathrm{kV}$, nebulizer pressure 2 bar, dry gas temperature $180{ }^{\circ} \mathrm{C}$, and dry gas flow rate 10 $\mathrm{L} / \mathrm{min}$. Spectra were collected from $\mathrm{m} / \mathrm{z} 50$ to $800 \mathrm{Da}$ at a rate of $2 \mathrm{~Hz}$. Sodium formate dissolved in $50 \%$ of 2-propanol was introduced into the ion source between $0.2-0.4 \mathrm{~min}$ for internal calibration of the data files. Hexakis $(1 \mathrm{H}, 1 \mathrm{H}, 2 \mathrm{H}$-perfluoroethoxy) phosphazene was used as the lock mass calibrant. 
To confirm the presence of pyrrolizidine alkaloids, LC-MS/MS analyses were conducted using broadband collision-induced dissociation (bbCID) with a fragmentation energy of $35 \mathrm{eV}$ and nitrogen as the collision gas.

\subsection{Design of validation}

Validation parameters such as linearity, specificity, limits of detection (LOD), limit of quantification (LOQ), measurement uncertainty, recovery, and precision were determined for 12 PAs using the established method according to Nordic Committee on Food Analysis (NMKL) procedure No. 4 with minor modification (NMKL, 2009). The spiked samples were prepared according to the procedure described above and analyzed on three different days. All 12 PA compounds were spiked at 4 concentration levels: $2 \mathrm{ng} / \mathrm{mL}, 10 \mathrm{ng} / \mathrm{mL}, 50 \mathrm{ng} / \mathrm{mL}$, and $150 \mathrm{ng} / \mathrm{mL}$ corresponding to $1 \mu \mathrm{g} / \mathrm{kg}, 5 \mu \mathrm{g} / \mathrm{kg}$, $25 \mu \mathrm{g} / \mathrm{kg}$, and $75 \mu \mathrm{g} / \mathrm{kg}$ in the honey samples. At each concentration level at least 10 replicates of the same spiked blank honey samples were analyzed (13 replicates at $10 \mathrm{ng} / \mathrm{mL}$, and 10 replicates for the other 3 levels). Method precision was evaluated by intra- and inter-day analyses. The repeatability (intra-day variability) was tested within one day for each concentration, reproducibility (inter-day variability) was examined on three different days for each concentration ( 13 replicates for $5 \mu \mathrm{g} / \mathrm{kg}, 10$ replicates for $1 \mu \mathrm{g} / \mathrm{kg}, 25 \mu \mathrm{g} / \mathrm{kg}$ and $75 \mu \mathrm{g} / \mathrm{kg}$ ).

LOD and LOQ were calculated by using the standard deviation of 10 replicates at $2 \mathrm{ng} / \mathrm{mL}$ (blank honey spiked before SPE clean-up). LOD $=3 \times \mathrm{SD} /$ recovery of each compound, LOQ $=6 \times \mathrm{SD} /$ recovery of each compound. Matrix effects (ME) was estimated by adding different levels of standard solution to a sample of the blank honey extracts. Matrix match calibration curves were used to correct for matrix effects (ME), and were made by analysis of each analyte at 7 calibration levels from 2 to 150 $\mathrm{ng} / \mathrm{mL}$. The standard curves were the peak area versus the concentration of each analyte. $\mathrm{ME}(\%)=$ 
191 (Slope of matrix match standard curve / Slope of standard curve without honey matrix) $\times 100 \%$. ME of 192 some other honey samples were also measured at $50 \mathrm{ng} / \mathrm{mL}$ spike level to compare the ME difference 193 between different honey samples. The recovery was determined by comparing the analytical results of 194 the extracted PAs from spike honey samples with the results of standards added in the same 195 concentrations to blank matrix (13 replicates for $5 \mu \mathrm{g} / \mathrm{kg}, 10$ replicates for $1 \mu \mathrm{g} / \mathrm{kg}, 25 \mu \mathrm{g} / \mathrm{kg}$ and 75 $196 \mu \mathrm{g} / \mathrm{kg})$.

\subsection{Quantification}

All the quantification was performed by integration of peak area of extracted ion chromatograms using exact mass $\pm 5 \mathrm{mDa}$. The concentration of PAs in the samples was calculated by QuantAnalysis 2.2 (Bruker Daltonics, Bremen, Germany). All the values of PAs of samples were calculated by using the average value in duplicate samples of the same sequence.

\subsection{Software}

The Chemdraw Professional 15.0 was used for drawing and displaying chemical structures. R 204 (version 3.3.3), R studio and Origin software were used for all statistical analysis. Jchem version 18.5.0 was used to predict the $\mathrm{p} K_{\mathrm{a}}, \mathrm{p} K_{\mathrm{b}}, \log \mathrm{P}$ values, and other properties of molecules.

\subsection{Statistical model evaluation and validation}

207 Several studies have investigated the relationship between signal response in electrospray ionizationmass spectrometry (ESI-MS) and molecular descriptors (molecular volume, $\log \mathrm{P}, \mathrm{p} K_{\mathrm{a}}$, polarity) of 209 analytes to estimate analyte concentration (Golubović et al., 2016; Kruve \& Kaupmees, 2017; Oss et 210 al., 2010). Seneciphylline was randomly chosen as the reference standard in the method to correct the 211 daily variation. Multi-linear regression (MLR) analysis was carried out to obtain the QPM describing 

the relationship between relative calibration curves' slope (RS) corresponding to seneciphylline in honey matrix and molecular properties in the following formula:

$$
\ln \mathrm{RS}=\ln \left(\frac{\text { Slope of analytes }}{\text { Slope of Seneciphylline }}\right)=\sum_{\boldsymbol{i}=\mathbf{1}}^{n} \boldsymbol{a}_{\boldsymbol{i}} \boldsymbol{X}_{\boldsymbol{i}}
$$

where $\boldsymbol{X}_{\boldsymbol{i}}$ is the physicochemical parameters or their combinations, and $\boldsymbol{a}_{\boldsymbol{i}}$ is the coefficients of these parameters. Experimental values of several parameters such as $\log \mathrm{P}$ and $\mathrm{p} K_{\mathrm{a}}$ are not available for all compounds, therefore these molecular descriptors including Molecular volume, $\log \mathrm{P}, \mathrm{p} K_{\mathrm{a}}$ (strongest acidic), $\mathrm{p} K_{\mathrm{b}}$ (strongest basic), and polarizability were computed by using Physico-chemical property predictors plugin of JChem in excel (Szisz, 2017). All the chemical structures of PAs were transferred as the SMILES (Simplified molecular input line entry specification) obtained from PubChem. The molecular descriptors with correlation above 0.9 were removed to avoid the co-linearity in the model. $\boldsymbol{X}_{\boldsymbol{i}}$ and $\boldsymbol{a}_{\boldsymbol{i}}$ were obtained by MLR which was calculated in R. Twelve PAs compounds were used to develop the MLR model (exact mass is in the range from 299 to $427 \mathrm{Da}, \mathrm{p} K_{\mathrm{a}}$ is in the range from 10.54 to $12.37, \mathrm{p} K_{\mathrm{b}}$ is in the range from 2.82 to $8.13, \log \mathrm{P}$ is in the range from -1.42 to 1.64$)$. In the gradient elution, all the PAs were eluted from $10 \%$ to $37 \%$ organic phase, which is considered as a narrow range, thus the corrections with retention parameters or solvent change was ignored in this part.

Cross-validation method 'leave-one-out' (LOO) approach was used to validate the obtained results. LOO means that each compound was left out from the model fitting process once; thereafter, the model was used to predict the RS value of the compound not involved in the model development. LOO is equivalent to $\mathrm{k}$-fold cross-validation where $\mathrm{k}=\mathrm{n}$ (the number of observations in the data set), and LOO for linear regression is exactly equivalent to the PRESS (Predicted Residual Sum of Squares) method based on the leave-one-out or Jackknife technique, detail explanation can be found in Tarpey's study 
233 (Tarpey, 2000). Therefore in this study, PRESS and root mean square error of prediction (RMSEP) 234 were used to describe the differences between predicted RS values and measured values.

235 Using the fact of the predicted value for $y_{i}$ when the $i^{\text {th }}$ compound is deleted from the MLR model 236 is equal to

$$
y_{i}-\hat{y}_{(i)}=\frac{\hat{e}_{i}}{\left(1-h_{i}\right)}=\hat{e}_{(i)}
$$

237 Here $\hat{e}_{i}=$ usual $i^{\text {th }}$ residual and $h_{i}=$ potential or leverage value for the $\mathrm{i}^{\mathrm{th}}$ compound,

$238 y_{i}$ and $\hat{y}_{(i)}$ are predicted and measured $\operatorname{lnRS}$ value in this study, respectively.

$$
\text { PRESS }=\sum_{i=1}^{n}\left(y_{i}-\hat{y}_{(i)}\right)^{2}
$$$$
R M S E P=\sqrt{\frac{P R E S S}{n}}
$$

240 The resulting model was also used to predict the slope of the calibration curves for 4 additional PAs 241 which were not included in the original dataset but within the model coverage to verify the prediction 242 quality. The predicted slopes were used to calculate the concentrations of the other PAs compounds 243 detected in the collected samples.

$$
C_{\text {predicted }}=\frac{\text { Response }_{\text {from sample }}}{\text { Slope }_{\text {predicted }}}
$$

$\mathrm{C}_{\text {predicted }}$ is the predicted PA concentration, Response $\mathrm{from} \mathrm{sample}_{\text {is }}$ ise peak area of the tentatively 246 identified PAs in honey samples, Slope predicted $_{\text {is }}$ the slope of predicted calibration curve of the 247 identified PAs, and it was calculated from the RS value corresponding to the slope value of reference 248 standard (seneciphylline) in honey matrix, assuming that the standard curve pass through zero. 
249 All statistical tests were performed at 95\% significant level. The prediction error for additional 4 PAs 250 out of the model was calculated with the following formula:

\section{RESULTS AND DISCUSSION}

\section{$253 \quad$ 3.1 PART 1. Validation}

254 3.1.1. Specificity

Blank honey samples and blank honey spiked with $5 \mathrm{ng} / \mathrm{ml} \mathrm{mix} \mathrm{standard} \mathrm{solution} \mathrm{(corresponding} \mathrm{to}$ $2562.5 \mu \mathrm{g} / \mathrm{kg}$ ) were analysed to examine if other compounds in the samples were interfering with these 257 analytes. The HPLC shows good separation of all 12 PA compounds, and there are no apparent 258 interferences observed from the matrix evaluated from the extracted ion chromatograms, thus 259 confirming the specificity. The structures and chromatogram of 12 PAs are shown in in Figure 1.

\subsubsection{Linearity}

261 A good linear relationship was observed based on correlation coefficients higher than 0.99 (from 2 $262 \mathrm{ng} / \mathrm{mL}$ to $150 \mathrm{ng} / \mathrm{mL}$ ). The average relative residual is less than $25 \%$ at all levels, and the intercepts 263 obtained are close to the theoretical value zero, demonstrating good consistency. Information about 264 residues plot can be found in in Supporting Information Figure S1. 


\subsubsection{Precision}

The standard deviations of all the PAs at different spiked levels were calculated. Results are shown in Table 2. Coefficient of Variation (CV\%) for the reproducibility is in the range from $6.3 \%$ to $21.6 \%$, and $\mathrm{CV} \%$ for the repeatability is in the range from $2.6 \%$ to $18.9 \%$, which is considered acceptable.

\subsubsection{Recovery}

The average recovery is $89 \%$ for all the 12 PA compounds, ranging from $79.2 \%$ to $104.4 \%$ with a standard deviation lower than $7.6 \%$ (Table 2), thus confirming a good reproducibility of the method and sufficient for reliable analysis.

\subsubsection{Limit of detection and limit of quantification}

Results are shown in Table 2. LOD values for the 12 PA compounds are in the range from $0.2 \mu \mathrm{g} / \mathrm{kg}$ to $0.6 \mu \mathrm{g} / \mathrm{kg}$, LOQ values of the $12 \mathrm{PA}$ compounds are in the range from $0.5 \mu \mathrm{g} / \mathrm{kg}$ to $1.3 \mu \mathrm{g} / \mathrm{kg}$, which are comparable to those reported in literatures (Bolechová et al., 2015; EFSA, 2012). Although there are studies which present methods with lower LOQs (BfR, 2013; Kowalczyk \& Kwiatek, 2018; Lucatello, Merlanti, Rossi, Montesissa, Capolongo, 2016), they all rely on MRM mode rather than full scan detection. These MRM method are very specific however MRM are blind to other PAs that may occur in samples. Figure S2 shows samples spiked with $1 \mathrm{ng} / \mathrm{mL}$ (corresponding to $\sim 0.5 \mu \mathrm{g} / \mathrm{kg}$ in honey) with peaks still clearly visible for all analytes, indicating that the calculated limits are realistic to detect and quantify for the 12 PA compounds. 


\subsubsection{Matrix effect}

The matrix effect (ME) of spiked blank honey sample with $1 \mathrm{~g}$ sample load is in the range from $81.0 \%$ to $112.3 \%$, indicating that the analytes' signals are only slightly influenced by the honey matrix (Table 2). In order to compare the difference of ME between different honey matrix, additional experiments were done to compare the ME. Examining these results showed a RSD\% in the range from $4 \%$ to $12 \%$ from ME of 8 honey samples, which indicates that it is feasible to use one blank matrix to quantify all the other honey samples. Full data are shown in Supporting Information Table S1.

\subsubsection{Measurement uncertainty}

The measurement uncertainty (MU) consists of intra-laboratory reproducibility ("CVR"), bias ("bias") calculated as $100 \%$ recovery, standard deviation on bias ("CVRbias/sqrt(n)") calculated as intra-laboratory standard deviation divided by square root of number of results, and standard deviation on matrix effect ("CVmatrix effect") listed in Table S1 in the Supporting Information. The method uncertainty was calculated as:

$\mathrm{MU}=\sqrt{\mathrm{CVR}^{2}+\text { bias }^{2}+\frac{\text { CVRbias }^{2}}{\mathrm{n}}+\text { CVRmatrixeffect }^{2}}$

Seneciphylline-N-oxide, with the highest bias $(100-82.4 \%=17.6 \%)$ had a MU of $22 \%$ $\left(\sqrt{11.9^{2}+17.6^{2}+\frac{11.9^{2}}{43}+7.1^{2}}\right)$.

\subsection{PART 2. PA detection and contents in honey samples}

\subsubsection{PA Quantification and identification}


301

The 12 PAs included as standards in this study were selected based on the ones reported most often and in highest concentrations in honey (EFSA, 2011), and they belong to 3 major PAs chemical groups found in honey:

- Senecionine-type PAs (Retrorsine, retrorsine $N$-oxide, senecionine, senecionine $N$-oxide, seneciphylline, seneciphylline $N$-oxide), which occur primarily in the Senecioneae spp. (Asteraceae family), but are also found in Crotalaria spp. (Fabaceae family);

- Lycopsamine-type PAs (Intermedine, intermedine $N$-oxide, lycopsamine, echimidine), which occur in the Boraginaceae family and in the Eupatorieae spp. (Asteraceae family);

- Heliotrine-type PAs (lasiocarpine, lasiocarpine $N$-oxide), which occur in Heliotropium spp. (Boraginaceae family) (Mulder, López, These, \& Preiss-weigert, 2015).

The LC-MS/MS chromatograms of 12 validated PAs in honey samples were characterized by comparing the fragments pattern with authentic standards. The fragmentation pattern of selected PAs, $\mathrm{C}-1$ (monoester or open-chained diester), and C-2 ( $N$-oxide open-chained diester) are shown in Figure S3 (Avula et al., 2015; These et al., 2013). A compilation of chemical formulas, accurate mass, fragment ions, retention time, and mass error of HRMS detection for 12 reference PAs are shown in Table 3. The $\mathrm{MS}^{2}$ broadband fragmentation spectrums show fragment ions at $\mathrm{m} / \mathrm{z} 172,156,138,136$, 120, 118, and 94 which are the most common and characteristic fragments from these PAs. These fragment ions are also well known in unsaturated necine ester type PAs and are similar to fragments reported in the literature (Avula et al., 2015; Beales et al., 2004; Schulz et al., 2015; These et al., 2013). Detailed information about fragment patterns of PAs found in this study are shown in supplemental Figure S4. 
The analyses showed that one or more of the 12 PA compounds were found in $60 \%$ of these samples.

The combined results are shown in Table 1. The concentration of each PA compound in the positive samples is in the range between 1.4 and $11.1 \mu \mathrm{g} / \mathrm{kg}$ honey and the total PAs contents are in the range of 1.4 to $14.2 \mu \mathrm{g} / \mathrm{kg}$ (the sum of the 12 PAs). The highest total PA content is found in honey $\mathrm{H} 27$.

The most frequently found PA is echimidine. Seven of the tested samples are positive with concentrations ranging from 1.4 to $3.4 \mu \mathrm{g} / \mathrm{kg}$, followed by intermedine and senecionine. These findings are in accordance with the results reported by Lucatello (et al, 2016), most likely because plants from the genus Echium, namely Echium italicum L., Echium vulgare L., and Echium plantagineum L. are widely distributed in the European region (Lucatello, Merlanti, Rossi, Montesissa, 2016). For echimidine in $\mathrm{H} 14, \mathrm{H} 25$ intermedine in $\mathrm{H} 3, \mathrm{H} 23$, retrosine $N$-oxide in $\mathrm{H} 12, \mathrm{H} 23$, lycopsamine in $\mathrm{H} 11$, $\mathrm{H} 16, \mathrm{H} 25, \mathrm{H} 29$, and senecionine in $\mathrm{H} 4$ and $\mathrm{H} 9$, they are below the LOQ value but are still detected in LC-MS. Information about extracted ion chromatograms of these detected PAs are shown in Figure S5. Although PAs are detected in almost half of the samples studied, they are not found in as high concentration as in other studies (Avula et al., 2015; Beales et al., 2004). The levels of the 12 validated and quantified PAs are so low that the honey can be accepted according to both BMDL 10 of EFSA to assess the carcinogenic risks of PAs $(237 \mu \mathrm{g} / \mathrm{kg}$ bw per day for chronic toxicity) and also BFR recommendation (maximal intake of $0.007 \mu \mathrm{g} / \mathrm{kg}$ bw per day) if consumers only consume a limited quantity of honey (see Table 1) (Dusemund et al, 2011; EFSA, 2017; BfR, 2013). However, food safety issues frequently originate from compounds that are not included or quantified by the analytical method. Therefore, a multi-target screening method including more PAs compounds is particularly important to predict potential risk from PAs in honey. 
A screening method monitoring 85 different PAs compounds based on elemental composition from the literature was used to detect if other PAs could be found in the honey samples. The PAs in the screening list were compiled from literatures and only 1, 2-un-saturated compounds were taken into consideration. Then the suspicious signals with same molecule weight were further analysed by LCMS/MS. Tentative identification of the PAs was done by comparing the fragments with literatures information (EFSA, 2011). Elemental composition and fragments ion of these tentative identified PAs from the screening method are shown in Table 3.

According to the screening results, several other PAs were found in the honey apart from the 12 validated PAs already quantified. Some of these PAs occur in relative high concentration. For example, a chromatographic peak just next to lycopsamine with the same protonated molecular ions (m/z reports and fragments information we obtained $(\mathrm{m} / \mathrm{z} 94.0655,138.0932 .156 .1019)$, this unknown compound is most likely rinderine (other possibilities are echinatine or indicine), and all of them are belong to lycopsamine-type PA stereoisomers, which include indicine, intermedine, lycopsamine, rinderine and echinatine (Beales et al., 2004; Kempf et al., 2011). All these five PAs are structurally

362 closely related, thus a similar retention behaviour and mass spectrometric response can be assumed to 363 be the same. There are also other large peaks appearing next to senecionine and echimidine again $(0.1$ 
min retention time difference) with the same molecule weight and fragment pattern, but not the same as verified by standard addition.

Several PAs have the similar molecular structures, therefore we will expect similar properties and fragments pattern in LC-MS/MS. For these types of compounds, it is difficult to predict the correct structures without further identification or authentic standard. Therefore, the data can only be seen as indicative. A list of considered PA compounds included in the screening, and their accurate mass data, are shown in Supporting Information Table S2.

To evaluate the concentrations of these other PAs, which were not included in the validation method, a semi-quantification approach was used to estimate their concentration as discussed in the following section.

\subsection{PART 3. QPM and estimation of concentration of other PAs in honey samples}

Estimation of the concentration for PAs where standards are unavailable are based on all the information we can obtain from direct measurement of available standards and honey samples, also model calculation. In the initial model, all the previously mentioned molecular properties (molecule volume, $\mathrm{p} K_{\mathrm{a},} \mathrm{p} K_{\mathrm{b}}, \log \mathrm{P}$, relative slope, exact mass, and retention time of 12 PAs used in the model and tentative identified PAs in samples are shown in Table S3a) were included. While by backward MLR modelling, the best fit for data was achieved with a model containing $\mathrm{p} K_{\mathrm{a}}, \mathrm{p} K_{\mathrm{b}}, \log \mathrm{P}$, and exact mass. Several authors have found that hydrophobicity $(\log \mathrm{P}$, usually expressed as octanol/water partition coefficient) are important characteristics correlated to ESI ionization efficiency, and increasing the extent of nonpolar character in a compound leads to enhanced affinity for the surface phase and higher ESI response (Cech \& Enke, 2000; Leito et al., 2008). pKa can be expressed as the ability to be 
protonated and become a cation, and it has been proved that $\mathrm{p} K \mathrm{a}$ is highly correlated with ionization efficiency in ESI (Oss et al., 2010). Exact mass was characterized by the molecular size or molecular volume, which also has been reported as a parameter that can influence ionization efficiency (Hermans, Ongay, Markov, \& Bischoff, 2017; Oss, Kruve, Herodes, \& Leito, 2010).

The formula calculated in $\mathrm{R}$ is shown in the following formula (Procedures of calculation is shown in Supporting Information).

$\ln \left(R S_{\text {predicted }}\right)=(27.0965 \pm 7.6792)+(1.0240 \pm 0.3192) \times \log \mathrm{P}-(1.4075 \pm 0.4115) \times \mathrm{p} K_{\mathrm{a}}-$ $(0.3048 \pm 0.1010) \times \mathrm{p} K_{\mathrm{b}}-(0.0285 \pm 0.0073) \times$ exact mass

Regarding the calculation, eg., rinderine, $\ln \left(R S_{\text {predicted }}\right)$ of rinderine $=27.0965+1.0240 \times(-0.2900)$ $1.4075 \times 11.3400-0.3048 \times 7.8200-0.0285 \times 299.1733=-0.07149$, therefore predicted relative slope of rinderine corresponding to seneciphylline is 0.9310 .

The correlation between predicted RS and measured RS is shown in Figure 2-a. The $\mathrm{R}^{2}$ for this model was 0.75 and the residual standard error was 0.21 logarithmic units. By LOO validation, the accuracy of the models can also be described with RMSEP, RMSEP $=0.28 \ln R S$ units. This value shows that on average the mismatch between the predicted and measured RS from LOO is lower than 1.3 times. The prediction errors are in the range from $-0.3 \%$ to $27.1 \%$ for the $12 \mathrm{PA}$ compounds used to develop the model (Table S3-b in Supporting Information). To validate the method, the model was also used to quantify 4 additional PAs compounds available as pure standards but not included in the model above in a spiking experiment. The concentrations of these 4 authentic standard compounds were estimated using the model developed by the 12 PAs giving a prediction error in the range between $10.2 \%$ and $50.8 \%$. Figure 2-b shows the difference in standard curve slope using the predicted concentration and 
measured concentration of the PAs not included in the model (from 5 to $100 \mathrm{ng} / \mathrm{mL}$ ). Therefore, a predicting model based on a 12 PAs calibration sets provides acceptable quantification results for a risk assessment. Despite some PAs being of different chemical structures, they share quite similar physicochemical properties, hence this will not have large effect on the predicted concentration. We also calculated the model based on the data we obtained from two different days; and the coefficients in the formula are quite similar as shown in Table S3-b. The difference between the two formulas obtained from two different experimental days was compared; the variation for all compounds is within a range of $-24.5 \%$ to $10.9 \%$. This indicates the feasibility for the future study, to use only one model and one reference PA standard (e.g., Seneciphylline in this study) to predict the concentrations of the other PAs within maximum 50.8\% prediction error; as long as we have the structures information of these PAs.

In many cases, studies about PAs estimation may choose calibration alkaloids of similar structure using different calibration alkaloids (often an isomer) (Hoogenboom et al., 2011; These et al., 2013). Or just simply reported all alkaloids as equivalent of one alkaloid such as echimidine in Beales' study (Beales et al., 2004). In the approach of PAs estimation with different calibration alkaloids, serveral PAs standards are still necessary. They cover various PAs types, while in the approach of PAs estimation, with only one alkaloid, it is more unpersuasive due to the variation of PAs response which can be nearly 3 times based on our results. Hereby, the difference between the approach of PAs estimation, with only one alkaloid and our prediction model, were compared. It is shown in Table S4 in Supporting Information, 3 concentrations ( $5 \mathrm{ng} / \mathrm{ml}, 10 \mathrm{ng} / \mathrm{ml}, 25 \mathrm{ng} / \mathrm{ml}$ ) were performed, and Max $25 \%$ (the sum of $25 \%$ biggest absolute prediction error, e.g., absolute prediction error of 4 PAs were chosen among 16 PAs in our case) was used to estimate the performance of different approaches. In the 
approach simply reported every alkaloid as equivalent of one alkaloid, the Max $25 \%$ values are in the range of $232.2 \% \sim 603.1 \%, 202.5 \% \sim 502.2 \%, 170.3 \% \sim 621.2 \%$ in the concentration of $5,10,25$ $\mathrm{ng} / \mathrm{ml}$, respectively. However, when we use the prediction model, the Max25\% values are $196.50 \%$, $142.16 \%, 162.26 \%$ separately, which is more accurate and controllable. It has been reported by the EFSA Scientific Panel on Contaminants in the Food Chain (CONTAM Panel) that they identify mainly 4 types of PAs of particular importance for food and feed (Senecionine-types, Lycopsamine-type, Heliotrine-type, Monocrotaline-type) (EFSA, 2011). Although there were only a limited number of PAs in our dataset when we developed the QPM, it covers 3 types of most common PAs which exist in honey. Therefore, this model can make relative accurate estimation of PAs covered by these 3 types, at least (only monocrotaline-type PAs was excluded). To make this model more generic, further study can be carried out to include more PAs, such as monocrotaline-type PAs in the model development.

The QPM was used for the estimation of other PAs based on the tentative identification, and prediction error of RS between measured and predicted value are shown in supplemental Table S3-b. The results from semi-quantification of these PAs are shown in Table 1. Riderine (or Echinatine /Indicine), which elutes just next to lycopsamine and shows the highest level among all the quantified PAs reaching an estimated concentration of about $56 \mu \mathrm{g} / \mathrm{kg}$ in $\mathrm{H} 15$. Crotananine shows the concentration of about $51 \mu \mathrm{g} / \mathrm{kg}$ in $\mathrm{H} 8$, followed by acetyl-lycopsamine and 3'-acetylindicine, with a concentration of $47 \mu \mathrm{g} / \mathrm{kg}$ and $45 \mu \mathrm{g} / \mathrm{kg}$ both detected in $\mathrm{H} 9$.

Although according to assessment of chronic risks referring to a $\mathrm{BMDL}_{10}$ of $237 \mu \mathrm{g} / \mathrm{kg}$ bw per day established by EFSA (EFSA, 2017) or acute toxicity data reported by Dusemund et al., (2011), the detected PAs levels are acceptable. However, following the recommendations from the BFR as 
mentioned before, the oral intake of PAs should not exceed a daily dose of $0.007 \mu \mathrm{g} / \mathrm{kg} \mathrm{b.w} \mathrm{(BfR,}$ 2011). Assuming that a $60 \mathrm{~kg}$ body weight and a daily consumption of honey of $20 \mathrm{~g}$, a honey sample should not contain more than $21 \mu \mathrm{g} / \mathrm{kg}$ of PAs. Our estimated concentration of PAs, including all PAs even those where standards are not available, show the total PAs content in honey samples may be as high as: H6 (ca. $26 \mu \mathrm{g} / \mathrm{kg}$ ), H7 (ca. $36 \mu \mathrm{g} / \mathrm{kg}$ ), H5 (ca. $36 \mu \mathrm{g} / \mathrm{kg}$ ), H11 (ca. $36 \mu \mathrm{g} / \mathrm{kg}$ ), H18 (ca. 41 $\mu \mathrm{g} / \mathrm{kg}$ ), H8 (ca. $51 \mu \mathrm{g} / \mathrm{kg}$ ), H15 (ca. $67 \mu \mathrm{g} / \mathrm{kg}$ ) and H9 (ca.117 $\mu \mathrm{g} / \mathrm{kg}$ ) all exceeding $21 \mu \mathrm{g} / \mathrm{kg}$. Even if we consider a quantification error of $51 \%$ the levels will still be of concern.

In conclusion, we proposed a method that can be extended to a general strategy to achieve estimation of quantitative data where authentic standards are not available. By using a prediction model based on physio-chemical parameters, analysis of similar standards, and literature relevant quantitative data for risk assessment can be estimated using HPLC-HR-MS/MS techniques. This approach was demonstrated by the simultaneous quantification of 12 PAs and also the further analysis of honey containing other high content PAs without standards. Future applications of this method could be the quantification or semi-quantification of PAs in other honey samples, and also other PA containing products, such as herbal tea, cereal, feed, and milk.

\section{ABBREVIATIONS USED}

PAs: Pyrrolizidine alkaloids; GC-MS: Gas chromatography-mass spectrometry; LC-MS: Liquid chromatography-mass spectrometry; MRM: multiple reaction-monitoring; LC-QTOF: liquid chromatography-quadrupole-time-of-flight-mass spectrometry; QC: Quality control; LOD: limits of detection; LOQ: limit of quantification; $\mathrm{p} K_{\mathrm{a}}: \mathrm{p} K_{\mathrm{a}}$ value of strongest acidic; $\mathrm{p} K_{\mathrm{b}}: \mathrm{p} K_{\mathrm{a}}$ value of strongest basic; SMILE: simplified molecular-input line-entry system; CV\%: Coefficient of Variation; ME: 
471 dose associated with a $10 \%$ response

\section{SUPPORTING INFORMATION DESCRIPTION}

Supplementary data related to this article can be found in the Supporting Information file.

\section{FUNDING SOURCE}

475 The study was financially supported by the Danish Food Authorities.

\section{ACKNOWLEDGEMENTS}

477 The authors would like to thank Helen Fodnæss for the proof reading.

\section{REFERENCE}

Alymatiri, C. M., Kouskoura, M. G., \& Markopoulou, C. K. (2015). Decoding the signal response of steroids in electrospray ionization mode (ESI-MS). Analytical Methods, 7, 10433-10444.

Avula, B., Sagi, S., Wang, Y. H., Zweigenbaum, J., Wang, M., \& Khan, I. A. (2015). Characterization and screening of pyrrolizidine alkaloids and N-oxides from botanicals and dietary supplements using UHPLC-high resolution mass spectrometry. Food Chemistry, 178, 136-148.

Beales, K. A., Betteridge, K., Colegate, S. M., \& Edgar, J. A. (2004). Solid-phase extraction and LCMS analysis of pyrrolizidine alkaloids in honeys. Journal of Agricultural and Food Chemistry, 52(21), 6664-6672. 
analysis of pyrrolizidine alkaloids and their N-oxides in honey: Application to Echium vulgare honeys. Journal of Agricultural and Food Chemistry, 53(6), 1894-1902.

BfR. (2011). Chemical analysis and toxicity of pyrrolizidine alkaloids and assessment of the health risks posed by their occurrence in honey.

BfR. (2013). Determination of pyrrolizidine alkaloids (PA) in honey by SPE-LC-MS/MS.

Bodi, D., Ronczka, S., Gottschalk, C., Behr, N., Skibba, A., Wagner, M., et al. (2014). Determination of pyrrolizidine alkaloids in tea, herbal drugs and honey. Food Additives \& Contaminants: Part A, 31(11), 1886-1895.

Bolechová, M., Čáslavský, J., Pospíchalová, M., \& Kosubová, P. (2015). UPLC-MS/MS method for determination of selected pyrrolizidine alkaloids in feed. Food Chemistry, 170, 265-270.

Boppré, M. (2011). The ecological context of pyrrolizidine alkaloids in food, feed and forage: an overview. Food Additives and Contaminants, 28(3), 260-281.

Boppré, M., Colegate, S. M., \& Edgar, J. A. (2005). Pyrrolizidine alkaloids of Echium vulgare honey found in pure pollen. Journal of Agricultural and Food Chemistry, 53, 594-600.

Cech, N. B., \& Enke, C. G. (2000), Relating electrospray ionization response to nonpolar character of small peptides. Analytical Chemistry, 72, 2717-2723.

Chung, S. W. C., \& Lam, C.-H. (2018). Development of an Analytical Method for Analyzing Pyrrolizidine Alkaloids in Different Groups of Food by UPLC-MS/MS. Journal of Agricultural and Food Chemistry, 66, 3009-3018.

Colegate, S. M., Edgar, J. A., Knill, A. M., \& Lee, S. T. (2005). Solid-phase extraction and HPLC-MS profiling of pyrrolizidine alkaloids and their N-oxides: a case study of Echium plantagineum. Phytochemical Analysis, 16, 108-119. 
Crews, C., Berthiller, F., \& Krska, R. (2010). Update on analytical methods for toxic pyrrolizidine alkaloids. Analytical and Bioanalytical Chemistry, 396, 327-338.

Culvenor, C. C. J., Edgar, J. A., Smith, L. W., Kumana, C. R., \& Lin, H. J. (1986). Heliotropium lasiocarpum Fisch and mey identified as cause of veno-occlusive disease due to a herbal tea. The Lancet, 978.

Dusemund, B., Nowak, N., Sommerfeld, C., Lindtner, O., Schäfer, B., \& Lampen, A. (2018). Risk assessment of pyrrolizidine alkaloids in food of plant and animal origin. Food and Chemical Toxicology, 115, 63-72

EFSA. (2011). Scientific Opinion on Pyrrolizidine alkaloids in food and feed. EFSA Journal, 9(11), 2406.

EFSA. (2012). Summary report of the standing committee on the food chain and animal health, held in Brussels on 11 July 2012, section toxicological safety of the food chain. https://doi.org/10.1093/oxfordhb/9780199546282.013.0024

EFSA. (2017). Risks for human health related to the presence of pyrrolizidine alkaloids in honey, tea, herbal infusions and food supplements. EFSA Journal, 15(7). 4908

Golubović, J., Birkemeyer, C., Protić, A., Otašević, B., ečević. M. (2016). Structure - response relationship in electrospray ionization-mass spectrometry of sartans by artificial neural networks. Journal of Chromatography A, 1438, 123-132.

Heeft, E., Bolck, Y. J. C., Beumer, B., Nijrolder, A.W. J. M., Stolker, A. A. M., \& Nielen, M. W. (2009). Combined with Time-of-Flight and Orbitrap. Journal of the American Society for Mass Spectrometry, 20, 451-463.

Hermans, J., Ongay, S., Markov, V., \& Bischoff, R. (2017). Physicochemical Parameters Affecting the 
Electrospray Ionization Efficiency of Amino Acids after Acylation. Analytical Chemistry, 89, 9159-9166.

Hoogenboom, L. A. P., Mulder, P. P. J., Zeilmaker, M. J., van den Top, H. J., Remmelink, G. J., Brandon, E. F. a, et al. (2011). Carry-over of pyrrolizidine alkaloids from feed to milk in dairy cows. Food Additives \& Contaminants. Part A, 28(3), 359-72.

Kempf, M., Wittig, M., Reinhard, A., von der Ohe, K., Blacquiere, T., Raezke, K.-P., et al. (2011). Pyrrolizidine alkaloids in honey: comparison of analytical methods. Food Additives and Contaminants Part A-Chemistry Analysis Control Exposure \& Risk Assessment, 28(3), 332-347.

Kowalczyk, E., \& Kwiatek, K. (2018). Pyrrolizidine alkaloids in honey: determination with liquid chromatography-mass spectrometry method. Journal of Veterinary Research, 62(2), 173-181.

Kruve, A., \& Kaupmees, K. (2017). Predicting ESI/MS signal change for anions in different solvents. Analytical Chemistry, 89, 5079-5086.

Leito, I., Herodes, K., Huopolainen, M., Virro, K., Künnapas, A., Kruve, A., \& Tanner, R. (2008). Towards the electrospray ionization mass spectrometry ionization efficiency scale of organic compounds. Rapid Communications in Mass Spectrometry, 22, 379-384.

Lucatello, L., Merlanti, R., Rossi, A., Montesissa, C., Capolongo, F. (2016). Evaluation of Some Pyrrolizidine Alkaloids in Honey Samples from the Veneto Region (Italy) by LC-MS/MS. Food Analytical Methods, 9, 1825-1836.

Lucchetti, M. A., Glauser, G., Kilchenmann, V., Dübecke, A., Beckh, G., Praz, C., \& Kast, C. (2016). Pyrrolizidine Alkaloids from Echium vulgare in Honey Originate Primarily from Floral Nectar. Journal of Agricultural and Food Chemistry, 64, 5267-5273.

Martinello, M., Cristofoli, C., Gallina, A., \& Mutinelli, F. (2014). Easy and rapid method for the 
quantitative determination of pyrrolizidine alkaloids in honey by ultra performance liquid chromatography-mass spectrometry: An evaluation in commercial honey. Food Control, 37(1), $146-152$.

Molyneux, R. J., Gardner, D. L., Colegate, S. M., \& Edgar, J. A. (2011). Pyrrolizidine alkaloid toxicity in livestock: a paradigm for human poisoning? Food Additives \& Contaminants: Part A, 28(3), $293-307$.

Mulder, P. P. J., Sánchez, L. P., These, A., \& Preiss-weigert, A. (2015). Occurrence of Pyrrolizidine Alkaloids in food. EFSA Supporting Publication, EN-859.

NMKL. (2009). NMKL Procedure No. 4. Validation of chemical analytical methods, 1-45. https://www.nmkl.org/index.php/en/.

Orantes-Bermejo, F. J., Serra Bonvehí, J., Gómez-Pajuelo, A., Megías, M., \& Torres, C. (2013). Pyrrolizidine alkaloids: their occurrence in Spanish honey collected from purple viper's bugloss (Echium spp.). Food Additives \& Contaminants: Part A, 30, 1799-1806.

Oss, M., Kruve, A., Herodes, K., \& Leito, I. (2010). Electrospray ionization efficiency scale of organic compound. Analytical Chemistry, 82, 2865-2872.

Raji, M. A., Fryčák, P., Temiyasathit, C., Kim, S. B., Mavromaras, G., Ahn, J.-M., \& Schug, K. A. (2009). Using multivariate statistical methods to model the electrospray ionization response of GXG tripeptides based on multiple physicochemical parameters. Rapid Communications in Mass Spectrometry, 23, 2221-2232.

Schulz, M., Meins, J., Diemert, S., Zagermann-Muncke, P., Goebel, R., Schrenk, D., et al. (2015). Detection of pyrrolizidine alkaloids in German licensed herbal medicinal teas. Phytomedicine, 22, 648-656. 
576 Szisz, D. (2017). pKa Plugin. Retrieved from http://www.weightless.org/about/spectrum-for-weightless 577 Tandon, R. K., Tandon, H. D., \& Narndranathan, M. (1976). An epidemic of veno-occlusive disease of $578 \quad$ liver in central Asia. The Lancet, 271-272.

579 Tarpey, T. (2000). A Note on the Prediction Sum of Squares Statistic for Restricted Least Squares. $580 \quad$ American Statistician, 54(2), 116-118.

581 These, A., Bodi, D., Ronczka, S., Lahrssen-wiederholt, M., \& Preiss-weigert, A. (2013). Structural 582 screening by multiple reaction monitoring as a new approach for tandem mass spectrometry: 583 presented for the determination of pyrrolizidine alkaloids in plants. Anal Bioanal Chem, 405, $584 \quad 9375-9383$.

585 Wiedenfeld, H. (2011). Plants containing pyrrolizidine alkaloids: toxicity and problems. Food 586 Additives and Contaminants, 28(3), 282-292. 


\section{TABLES}

Table 1. Information of all the tested honey samples: places of production, origins and symbols used in the text.

\begin{tabular}{|c|c|c|c|}
\hline No & $\begin{array}{c}\text { Geographical } \\
\text { origin }\end{array}$ & Botanical origin & PAs $\quad(\mu \mathrm{g} / \mathbf{k g})$ \\
\hline H1 & Spain & Mandarin honey & \\
\hline $\mathrm{H} 2$ & Romania & Creamy flowers honey & Echimidine (1.4) \\
\hline $\mathrm{H} 3$ & $\begin{array}{l}\text { Mixture from } \\
\text { outside the EU }\end{array}$ & Not clear & $\begin{array}{l}\text { Intermedine }(<\mathrm{LOQ}) \text {, Rinderine//Echinatine/Indicine (ca. } \\
6.1)\end{array}$ \\
\hline $\mathrm{H} 4$ & $\begin{array}{l}\text { Argentina and } \\
\text { Ukraine }\end{array}$ & Not clear & Echimidine (3.4), Senecionine $(<\mathrm{LOQ})$ \\
\hline H5 & China & $\begin{array}{l}\text { Mountain honey (many } \\
\text { wild flowers) }\end{array}$ & $\begin{array}{l}\text { Integerrimine/ Senecivernine (ca.1.6), Trichodesmine } \\
\text { (ca. 33.9) }\end{array}$ \\
\hline H6 & Mexico & Not clear & $\begin{array}{l}\text { Intermedine (3.5), Lycopsamine (1.7), Retrorsine (4.3), } \\
\text { Rinderine//Echinatine/Indicine (ca.16.4) }\end{array}$ \\
\hline $\mathrm{H} 7$ & Brazil & $\mathrm{N}$ & $\begin{array}{l}\text { Echimidine (1.6), Intermedine (2.3), Lycopsamine (2.2), } \\
\text { Retrorsine (1.6), Senecionine (2.4), } \\
\text { Rinderine//Echinatine/Indicine (ca.16.5), Integerrimine/ } \\
\text { Senecivernine (ca.9.5) }\end{array}$ \\
\hline H8 & Denmark & Clover and rape & Crotananine $(\sim 51.0)$ \\
\hline H9 & Denmark & er flowers honey & $\begin{array}{c}\text { Senecionine (<LOQ), Crotananine (ca.24.7), 3'- } \\
\text { acetylindicine (ca.45.4), Acetyl-lycopsamine (ca.46.8) }\end{array}$ \\
\hline $\mathrm{H} 10$ & Denmark & $\begin{array}{l}\text { Fruit trees (apple, plum, } \\
\text { rape) }\end{array}$ & Crotananine $(\sim 14.2)$ \\
\hline H11 & Denmark & $\begin{array}{l}\text { Summer flowers and } \\
\text { white clover honey }\end{array}$ & $\begin{array}{c}\text { Lycopsamine (<LOQ), Myoscorpine } N \text {-oxide/Echiumine } \\
N \text {-oxide/ Echiupinine- } N \text {-oxide (ca. } 2.7-3.2), \\
\text { Rinderine//Echinatine/ Indicine (ca.10.3), Crotananine } \\
\text { (ca.7.8), 3'-acetylindicine (ca.8.8),Acetyl-lycopsamine } \\
\text { (ca.6.7) }\end{array}$ \\
\hline H12 & Brazil & Not clear & Retrorsine- $N$-oxide $(<\mathrm{LOQ})$ \\
\hline H13 & Nicaragua & Mountain honey (many & Crotananine (ca.5.2) \\
\hline
\end{tabular}




\section{wild flowers)}

H14 Ukraine

Fruit trees

Mixture from

H15 countries inside and outside the EU

H16

H17

Mixture from outside the EU

H18 South America

H19

$\mathrm{H} 20$

H21

$\mathrm{H} 22$

$\mathrm{H} 23$

$\mathrm{H} 24$

H25

H26

H27

H28

Not clear

Not clear

Not clear

Not clear

Fruit trees

Not clear

Acacia

Not clear

Not clear

Acacia honey with

hazelnuts outside the EU
Not clear

Acacia

Mixture from

Denmark

Argentina and

Ukraine

China

Not clear

Not clear
Echimidine (<LOQ)

Intermedine (8.4), Lycopsamine (2.0), Rinderine//Echinatine/Indicine (ca.56.4),

Echimidine (2.2)

Crotananine (ca.3.4)

Intermedine (8.0), Lycopsamine (0.8),

Rinderine//Echinatine/Indicine (ca.31.7)

Crotananine (ca.7.7), Rinderine//Echinatine/Indicine (ca.1.1)

Echimidine (2.0), Crotananine ( 2.0)

Riddelline/Jacozine (ca.1.5-4.9)

Retrorsine (8.2), Crotananine (ca. 2.6),

Rinderine//Echinatine/Indicine (ca. 2.5)

Intermedine (<LOQ), Retrorsine (8.2), Retrorsine- $N$ -

oxide (<LOQ), Crotananine (ca. 4.4),

Rinderine//Echinatine/Indicine (ca. 3.6)

Crotananine (ca. 1.8)

Echimidine (<LOQ), Lycopsamine (<LOQ),

Intermedine (11.1), Lycopsamine (3.1)

Crotananine (ca. 5.3), Riddelline/ Jacozine (ca. 2.3-7.5),

Rinderine//Echinatine/Indicine (ca. 1.5) 


\begin{tabular}{|c|c|c|c|}
\hline $\mathrm{H} 29$ & $\begin{array}{c}\text { Mixture from } \\
\text { countries inside and } \\
\text { outside the EU }\end{array}$ & Wild flower & $\begin{array}{l}\text { Echimidine (2.7), Lycopsamine (<LOQ), Crotananine } \\
\text { (ca. 2.1) }\end{array}$ \\
\hline H30 & $\begin{array}{l}\text { Mixture from } \\
\text { countries inside and } \\
\text { outside the EU }\end{array}$ & Acacia & - \\
\hline H31 & $\begin{array}{l}\text { Mixture from } \\
\text { outside the EU }\end{array}$ & Not clear & $\begin{array}{c}\text { Echimidine (1.6), Intermedine (1.4), Lycopsamine (0.7), } \\
\text { Crotananine (ca. 12.8), Rinderine//Echinatine/Indicine } \\
\text { (ca. 3.3) }\end{array}$ \\
\hline H32 & $\begin{array}{l}\text { Mixture from } \\
\text { outside the EU }\end{array}$ & Not clear & \\
\hline
\end{tabular}


Table 2. Validation results.

\begin{tabular}{|c|c|c|c|c|c|c|c|c|c|c|c|c|}
\hline \multirow[t]{2}{*}{ Compounds } & \multirow[t]{2}{*}{ Conc } & & \multicolumn{3}{|c|}{ Inter-day reproducibility } & \multicolumn{3}{|c|}{ Intra-day Repeatability } & \multirow{2}{*}{$\begin{array}{c}\text { Recovery } \\
\% \\
\end{array}$} & \multirow{2}{*}{\multicolumn{2}{|c|}{$\begin{array}{c}\text { LOD LOQ } \\
\mu \mathrm{g} / \mathrm{kg}\end{array}$}} & \multirow{2}{*}{ ME } \\
\hline & & & mean & std & $\mathrm{CV} \%$ & mean & std & $\mathrm{CV} \%$ & & & & \\
\hline \multirow{4}{*}{ Echimidine } & 1.00 & $\mu \mathrm{g} / \mathrm{kg}$ & 0.89 & 0.19 & 21.6 & 0.89 & 0.17 & 18.8 & 93.5 & \multirow{4}{*}{0.54} & \multirow{4}{*}{1.07} & \multirow{4}{*}{101.92} \\
\hline & 5.00 & $\mu \mathrm{g} / \mathrm{kg}$ & 5.22 & 0.64 & 12.3 & 5.22 & 0.52 & 10.0 & 104.4 & & & \\
\hline & 25.00 & $\mu \mathrm{g} / \mathrm{kg}$ & 24.20 & 2.88 & 11.9 & 24.20 & 2.08 & 8.6 & 96.8 & & & \\
\hline & 75.00 & $\mu \mathrm{g} / \mathrm{kg}$ & 67.96 & 5.80 & 8.5 & 67.96 & 1.80 & 2.6 & 90.6 & & & \\
\hline \multirow[t]{4}{*}{ Intermedine } & 1.00 & $\mu \mathrm{g} / \mathrm{kg}$ & 0.81 & 0.08 & 10.3 & 0.81 & 0.07 & 8.0 & 89.4 & \multirow{4}{*}{0.41} & \multirow{4}{*}{0.81} & \multirow{4}{*}{90.50} \\
\hline & 5.00 & $\mu \mathrm{g} / \mathrm{kg}$ & 4.06 & 0.69 & 17.0 & 4.06 & 0.46 & 11.3 & 81.2 & & & \\
\hline & 25.00 & $\mu \mathrm{g} / \mathrm{kg}$ & 24.21 & 2.12 & 8.8 & 24.21 & 0.81 & 3.4 & 96.8 & & & \\
\hline & 75.00 & $\mu \mathrm{g} / \mathrm{kg}$ & 72.45 & 7.74 & 10.7 & 72.45 & 3.38 & 4.7 & 96.6 & & & \\
\hline \multirow[t]{4}{*}{ Intermedine- $N$-oxide } & 1.00 & $\mu \mathrm{g} / \mathrm{kg}$ & 0.96 & 0.16 & 16.9 & 0.96 & 0.16 & 16.9 & 95.6 & \multirow{4}{*}{0.52} & \multirow{4}{*}{1.04} & \multirow{4}{*}{94.05} \\
\hline & 5.00 & $\mu \mathrm{g} / \mathrm{kg}$ & 4.01 & 0.76 & 18.9 & 4.01 & 0.76 & 18.9 & 80.2 & & & \\
\hline & 25.00 & $\mu \mathrm{g} / \mathrm{kg}$ & 22.77 & 2.53 & 11.1 & 22.77 & 1.48 & 6.5 & 91.1 & & & \\
\hline & 75.00 & $\mu \mathrm{g} / \mathrm{kg}$ & 72.71 & 7.53 & 10.4 & 72.71 & 4.54 & 6.2 & 96.9 & & & \\
\hline \multirow[t]{4}{*}{ Lasiocarpine } & 1.00 & $\mu \mathrm{g} / \mathrm{kg}$ & 0.81 & 0.11 & 13.4 & 0.81 & 0.07 & 8.6 & 80.5 & \multirow{4}{*}{0.22} & \multirow{4}{*}{0.45} & \multirow{4}{*}{112.28} \\
\hline & 5.00 & $\mu \mathrm{g} / \mathrm{kg}$ & 4.19 & 0.59 & 14.1 & 4.19 & 0.24 & 5.8 & 83.8 & & & \\
\hline & 25.00 & $\mu \mathrm{g} / \mathrm{kg}$ & 23.57 & 3.20 & 13.6 & 23.57 & 1.30 & 5.5 & 94.3 & & & \\
\hline & 75.00 & $\mu \mathrm{g} / \mathrm{kg}$ & 68.47 & 8.95 & 13.1 & 68.47 & 3.65 & 5.3 & 91.3 & & & \\
\hline \multirow[t]{4}{*}{ Lasiocarpine- $N$-oxide } & 1.00 & $\mu \mathrm{g} / \mathrm{kg}$ & 0.81 & 0.15 & 18.6 & 0.81 & 0.15 & 18.6 & 81.4 & \multirow{4}{*}{0.60} & \multirow{4}{*}{1.20} & \multirow{4}{*}{97.10} \\
\hline & 5.00 & $\mu \mathrm{g} / \mathrm{kg}$ & 4.23 & 0.57 & 13.5 & 4.23 & 0.41 & 9.6 & 84.7 & & & \\
\hline & 25.00 & $\mu \mathrm{g} / \mathrm{kg}$ & 22.42 & 2.14 & 9.5 & 22.42 & 1.16 & 5.2 & 89.7 & & & \\
\hline & 75.00 & $\mu \mathrm{g} / \mathrm{kg}$ & 68.65 & 4.58 & 6.7 & 68.65 & 2.91 & 4.2 & 91.5 & & & \\
\hline \multirow[t]{4}{*}{ Lycopsamine } & 1.00 & $\mu \mathrm{g} / \mathrm{kg}$ & 0.83 & 0.10 & 12.3 & 0.83 & 0.08 & 9.4 & 82.7 & & & \\
\hline & 5.00 & $\mu \mathrm{g} / \mathrm{kg}$ & 4.65 & 0.61 & 13.1 & 4.65 & 0.54 & 11.5 & 93.0 & & & \\
\hline & 25.00 & $\mu \mathrm{g} / \mathrm{kg}$ & 22.68 & 3.86 & 17.0 & 22.68 & 0.81 & 3.6 & 90.7 & 0.28 & 0.56 & 90.68 \\
\hline & 75.00 & $\mu \mathrm{g} / \mathrm{kg}$ & 71.06 & 8.94 & 12.6 & 71.06 & 1.87 & 2.6 & 94.7 & & & \\
\hline Retrorsine & 1.00 & $\mu \mathrm{g} / \mathrm{kg}$ & 0.96 & 0.14 & 15.1 & 0.96 & 0.14 & 15.1 & 95.5 & & & \\
\hline & 5.00 & $\mu \mathrm{g} / \mathrm{kg}$ & 4.66 & 0.93 & 20.0 & 4.66 & 0.62 & 13.3 & 93.1 & 0.34 & 0.67 & 91.55 \\
\hline & 25.00 & $\mu \mathrm{g} / \mathrm{kg}$ & 22.94 & 3.05 & 13.3 & 22.94 & 2.59 & 11.3 & 91.8 & & & \\
\hline
\end{tabular}




\begin{tabular}{|c|c|c|c|c|c|c|c|c|c|c|c|c|}
\hline \multirow{3}{*}{ Retrorsine- $N$-oxide } & 75.00 & $\mu \mathrm{g} / \mathrm{kg}$ & 69.08 & 6.10 & 8.8 & 69.08 & 2.35 & 3.4 & 92.1 & \multirow{5}{*}{0.64} & \multirow{5}{*}{1.27} & \multirow{5}{*}{81.01} \\
\hline & 1.00 & $\mu \mathrm{g} / \mathrm{kg}$ & 0.79 & 0.10 & 12.9 & 0.79 & 0.10 & 12.9 & 79.2 & & & \\
\hline & 5.00 & $\mu \mathrm{g} / \mathrm{kg}$ & 4.31 & 0.77 & 17.9 & 4.31 & 0.77 & 17.9 & 86.2 & & & \\
\hline \multirow{5}{*}{ Senecionine } & 25.00 & $\mu \mathrm{g} / \mathrm{kg}$ & 23.69 & 3.42 & 14.4 & 23.69 & 1.47 & 6.2 & 94.8 & & & \\
\hline & 75.00 & $\mu \mathrm{g} / \mathrm{kg}$ & 70.80 & 9.91 & 14.0 & 70.80 & 3.47 & 4.9 & 94.4 & & & \\
\hline & 1.00 & $\mu \mathrm{g} / \mathrm{kg}$ & 0.81 & 0.13 & 16.5 & 0.81 & 0.13 & 16.5 & 81.4 & \multirow{4}{*}{0.45} & \multirow{4}{*}{0.91} & \multirow{4}{*}{82.95} \\
\hline & 5.00 & $\mu \mathrm{g} / \mathrm{kg}$ & 4.19 & 0.83 & 19.9 & 4.19 & 0.76 & 18.2 & 83.9 & & & \\
\hline & 25.00 & $\mu \mathrm{g} / \mathrm{kg}$ & 22.91 & 2.92 & 12.7 & 22.91 & 1.03 & 4.5 & 91.6 & & & \\
\hline \multirow{5}{*}{ Senecionine- $N$-oxide } & 75.00 & $\mu \mathrm{g} / \mathrm{kg}$ & 69.81 & 11.96 & 17.1 & 69.81 & 5.01 & 7.2 & 93.1 & & & \\
\hline & 1.00 & $\mu \mathrm{g} / \mathrm{kg}$ & 0.80 & 0.14 & 17.8 & 0.80 & 0.14 & 17.8 & 79.8 & \multirow{4}{*}{0.42} & \multirow{4}{*}{0.84} & \multirow{4}{*}{99.93} \\
\hline & 5.00 & $\mu \mathrm{g} / \mathrm{kg}$ & 4.18 & 0.81 & 19.5 & 4.18 & 0.52 & 12.5 & 83.5 & & & \\
\hline & 25.00 & $\mu \mathrm{g} / \mathrm{kg}$ & 22.58 & 2.66 & 11.8 & 22.58 & 1.98 & 8.8 & 90.3 & & & \\
\hline & 75.00 & $\mu \mathrm{g} / \mathrm{kg}$ & 68.89 & 6.05 & 8.8 & 68.89 & 3.41 & 5.0 & 91.9 & & & \\
\hline \multirow[t]{4}{*}{ Seneciphylline } & 1.00 & $\mu \mathrm{g} / \mathrm{kg}$ & 0.79 & 0.05 & 6.5 & 0.79 & 0.05 & 6.5 & 79.2 & \multirow{4}{*}{0.23} & \multirow{4}{*}{0.45} & \multirow{4}{*}{81.55} \\
\hline & 5.00 & $\mu \mathrm{g} / \mathrm{kg}$ & 4.12 & 0.63 & 15.2 & 4.12 & 0.52 & 12.7 & 82.4 & & & \\
\hline & 25.00 & $\mu \mathrm{g} / \mathrm{kg}$ & 22.20 & 2.18 & 9.8 & 22.20 & 1.46 & 6.6 & 88.8 & & & \\
\hline & 75.00 & $\mu \mathrm{g} / \mathrm{kg}$ & 67.64 & 4.50 & 6.6 & 67.64 & 2.57 & 3.8 & 90.2 & & & \\
\hline \multirow[t]{4}{*}{ Seneciphylline- $N$-oxide } & 1.00 & $\mu \mathrm{g} / \mathrm{kg}$ & 0.84 & 0.15 & 17.5 & 0.84 & 0.13 & 15.4 & 84.4 & \multirow{4}{*}{0.60} & \multirow{4}{*}{1.19} & \multirow{4}{*}{88.53} \\
\hline & 5.00 & $\mu \mathrm{g} / \mathrm{kg}$ & 4.17 & 0.52 & 12.5 & 4.17 & 0.52 & 12.5 & 83.5 & & & \\
\hline & 25.00 & $\mu \mathrm{g} / \mathrm{kg}$ & 19.80 & 2.26 & 11.4 & 19.80 & 1.31 & 6.6 & 79.2 & & & \\
\hline & 75.00 & $\mu \mathrm{g} / \mathrm{kg}$ & 61.75 & 3.90 & 6.3 & 61.75 & 2.70 & 4.4 & 82.3 & & & \\
\hline
\end{tabular}


Table 3. Molecular ions and selected MS/MS fragment ions of major PAs.

\begin{tabular}{|c|c|c|c|c|c|c|}
\hline RT & PAs $(\mu \mathrm{g} / \mathrm{kg})$ & Formula & $\begin{array}{c}{[\mathrm{M}+\mathrm{H}]^{+}} \\
\text {calculated }\end{array}$ & $\begin{array}{c}{[\mathrm{M}+\mathrm{H}]^{+}} \\
\text {experimental }\end{array}$ & $\begin{array}{c}\text { Fragment pattern and } \\
\text { abundancy }\end{array}$ & $\begin{array}{l}\text { Error } \\
(\mathrm{ppm})\end{array}$ \\
\hline 7.6 & Echimidine & $\mathrm{C}_{20} \mathrm{H}_{31} \mathrm{NO}_{7}$ & 398.2173 & 398.2170 & $\begin{array}{c}120.0810(48), \\
220.1301(2)\end{array}$ & -0.75 \\
\hline 4.3 & Intermedine & $\mathrm{C}_{15} \mathrm{H}_{25} \mathrm{NO}_{5}$ & 300.1805 & 300.1800 & $\begin{array}{l}138.0916(33), \\
156.1021(100)\end{array}$ & -1.66 \\
\hline 5.2 & $\begin{array}{l}\text { Intermedine } N \text { - } \\
\text { oxide }\end{array}$ & $\mathrm{C}_{15} \mathrm{H}_{25} \mathrm{NO}_{6}$ & 316.1755 & 316.1751 & $\begin{array}{l}138.0914(42), \\
172.0961(100)\end{array}$ & -1.27 \\
\hline 8.2 & Lasiocarpine & $\mathrm{C}_{21} \mathrm{H}_{33} \mathrm{NO}_{7}$ & 412.2330 & 412.2333 & $\begin{array}{c}120.0815(100) \\
238.1427(5)\end{array}$ & -0.73 \\
\hline 8.5 & $\begin{array}{l}\text { Lasiocarpine } N \text { - } \\
\quad \text { oxide }\end{array}$ & $\mathrm{C}_{21} \mathrm{H}_{33} \mathrm{NO}_{8}$ & 428.2279 & 428.2262 & $\begin{array}{c}94.0651(19), 120.0806 \\
(73), 138.0908(51)\end{array}$ & -3.96 \\
\hline 4.5 & Lycopsamine & $\mathrm{C}_{15} \mathrm{H}_{25} \mathrm{NO}_{5}$ & 300.1805 & 300.1805 & $\begin{array}{l}138.0917(28), \\
156.1020(100)\end{array}$ & 0 \\
\hline 6.1 & Retrorsine & $\mathrm{C}_{18} \mathrm{H}_{25} \mathrm{NO}_{6}$ & 352.1755 & 352.1744 & $\begin{array}{c}120.0822(100), \\
138.0894(58)\end{array}$ & -3.12 \\
\hline 6.3 & $\begin{array}{l}\text { Retrorsine- } N \text { - } \\
\text { oxide }\end{array}$ & $C, H$ & 368.1704 & 368.1707 & $\begin{array}{c}118.0648(100), \\
136.0765(52)\end{array}$ & 0.81 \\
\hline 7.2 & Senecionine & $\mathrm{C}_{18} \mathrm{H}_{25} \mathrm{NO}_{5}$ & 336.1805 & 336.1792 & $\begin{array}{l}120.0810(98) \\
138,0906(33)\end{array}$ & -3.87 \\
\hline 7.4 & $\begin{array}{l}\text { Senecionine } N- \\
\text { oxide }\end{array}$ & $\mathrm{C}_{18} \mathrm{H}_{25} \mathrm{NO}_{6}$ & 352.1755 & 352.1753 & $\begin{array}{c}94.0645(26), 118.0649 \\
(94), 136.0741(77)\end{array}$ & -0.56 \\
\hline 6.5 & Seneciphylline & $\mathrm{C}_{18} \mathrm{H}_{23} \mathrm{NO}_{5}$ & 334.1649 & 334.1655 & $\begin{array}{c}120.1818(100) \\
138.0911(66)\end{array}$ & 1.79 \\
\hline 6.8 & $\begin{array}{c}\text { Seneciphylline } N \text { - } \\
\text { oxide }\end{array}$ & $\mathrm{C}_{18} \mathrm{H}_{23} \mathrm{NO}_{6}$ & 350.1598 & 350.1595 & $\begin{array}{c}120.0827(100), \\
136.0748(41)\end{array}$ & -0.85 \\
\hline
\end{tabular}

\section{Tentative identified PAs}

$\begin{array}{lllllll}7.8 & \text { 3'-acetylindicine } & \mathrm{C}_{17} \mathrm{H}_{27} \mathrm{NO}_{6} & 342.1911 & 342.1910 & 94.0699(7), 121.0680 & -0.29\end{array}$


(81), $120.0813(25)$

8.1 Acetyl- $\quad \mathrm{C}_{17} \mathrm{H}_{27} \mathrm{NO}_{6} \quad 342.1911 \quad 342.1911$ lycopsamine

7.1 Crotananine

$\mathrm{C}_{17} \mathrm{H}_{25} \mathrm{NO}_{5}$

324.1805

Echinatine

4.6 /Indicine/Rinderi

$$
\mathrm{C}_{15} \mathrm{H}_{25} \mathrm{NO}_{5}
$$

300.1805

ne

7.1 Integerrimine/

$\mathrm{C}_{18} \mathrm{H}_{25} \mathrm{NO}_{5}$

336.1805

Senecivernine

$\mathrm{C}_{18} \mathrm{H}_{23} \mathrm{NO}_{6}$

350.1598

/Riddelline

Myoscorpine $N$ -

7.5 oxide/Echiumine

$\mathrm{N}$-oxide

5.2 Trichodesmine
$\mathrm{C}_{20} \mathrm{H}_{31} \mathrm{NO}_{7} \quad 398.2173$
$\mathrm{C}_{18} \mathrm{H}_{27} \mathrm{NO}_{6}$
324.1793

300.1795

120.0791 (46), 156.0903

(8)

0

120.0768(92),

138.0907 (18)

138.0912 (100).

156.0986 (28)

120.0796 (100),

138.0904 (54)

2.38

120.0772 (33.9),

138.0963 (6)

2

120.0807 (56),

398.2184

136.0693(2), 172.1412

3.26

(15)

94.0700(17),

120.0810 (100) 


\section{FIGURE CAPTIONS}

Figure 1. Structures and chromatogram of 12 PAs

(a) Chemical structures of 12 PAs.

(b) Chromatogram of $12 \mathrm{PAs}$ in $5 \mathrm{ng} / \mathrm{ml}$ spiked blank honey sample: 1. Intermedine, 2. Lycopsamine, 3. Intermedine $N$-oxide, 4. Retrosine, 5. Retrosine $N$-oxide, 6. Seneciphylline, 7. Seneciphylline $N$-oxide, 8. Senecionine, 9. Senecionine $N$-oxide, 10. Echimidine, 11. Lasiocarpine, 12. Lasiocarpine $N$-oxide.

Figure 2. (a) Correlation between relative predicted slope and measured slope in all PAs corresponding to Seneciphylline. (b) Correlation between predicted concentration and measured concentration in PAs (from 5 to $100 \mathrm{ng} / \mathrm{mL}$ ) out of the model. Note: Lycopsamine $N$-oxide, heliotrine, heliotrine $N$-oxide, 7 -acetylintermedine are 4 other PAs out of the 12 PAs in the model that used for verification of the prediction model. 


\section{FIGURE GRAPHICS}

\section{Figure 1.}

(a)
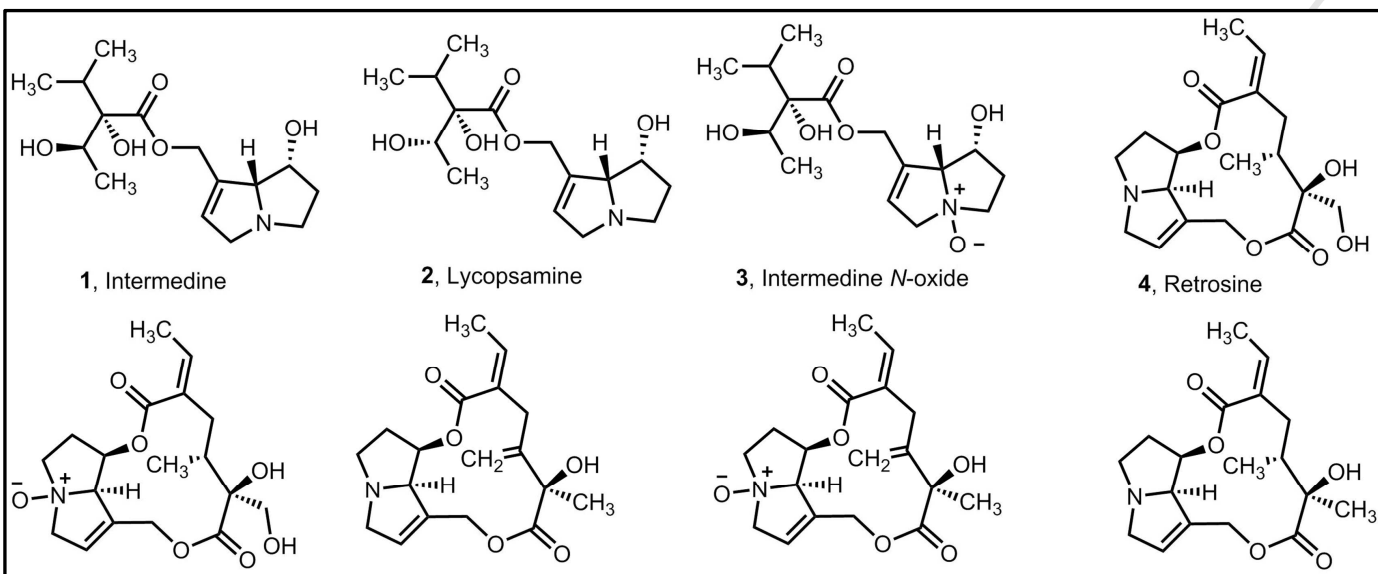

3, Intermedine $\mathrm{N}$-oxide

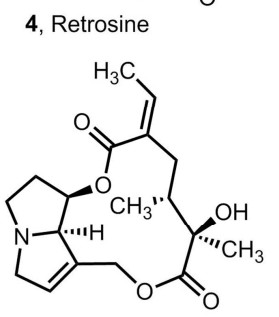

5. Retrosine $\mathrm{N}$-oxide

6, Seneciphylline

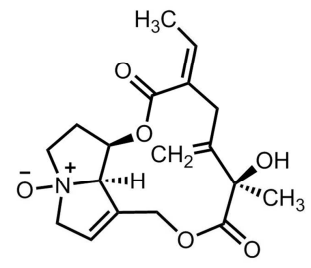

7, Seneciphylline $\mathrm{N}$-oxide

8, Senecionine
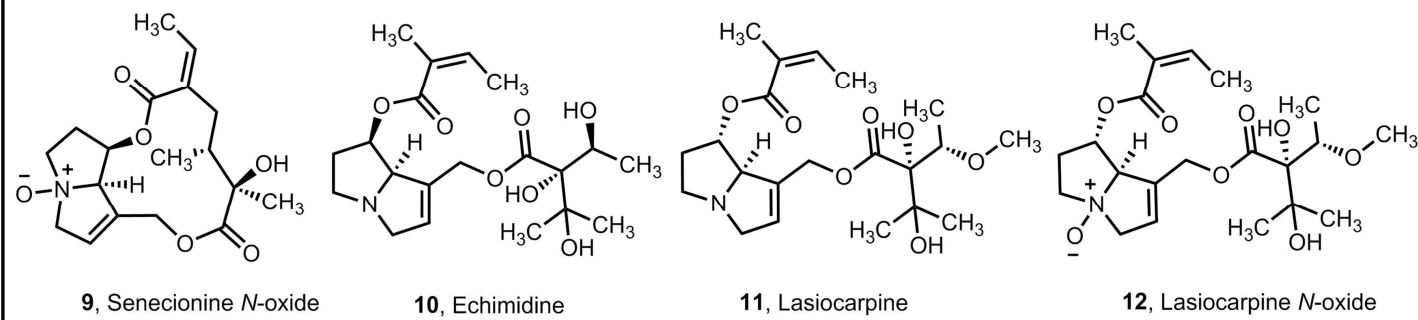

(b)

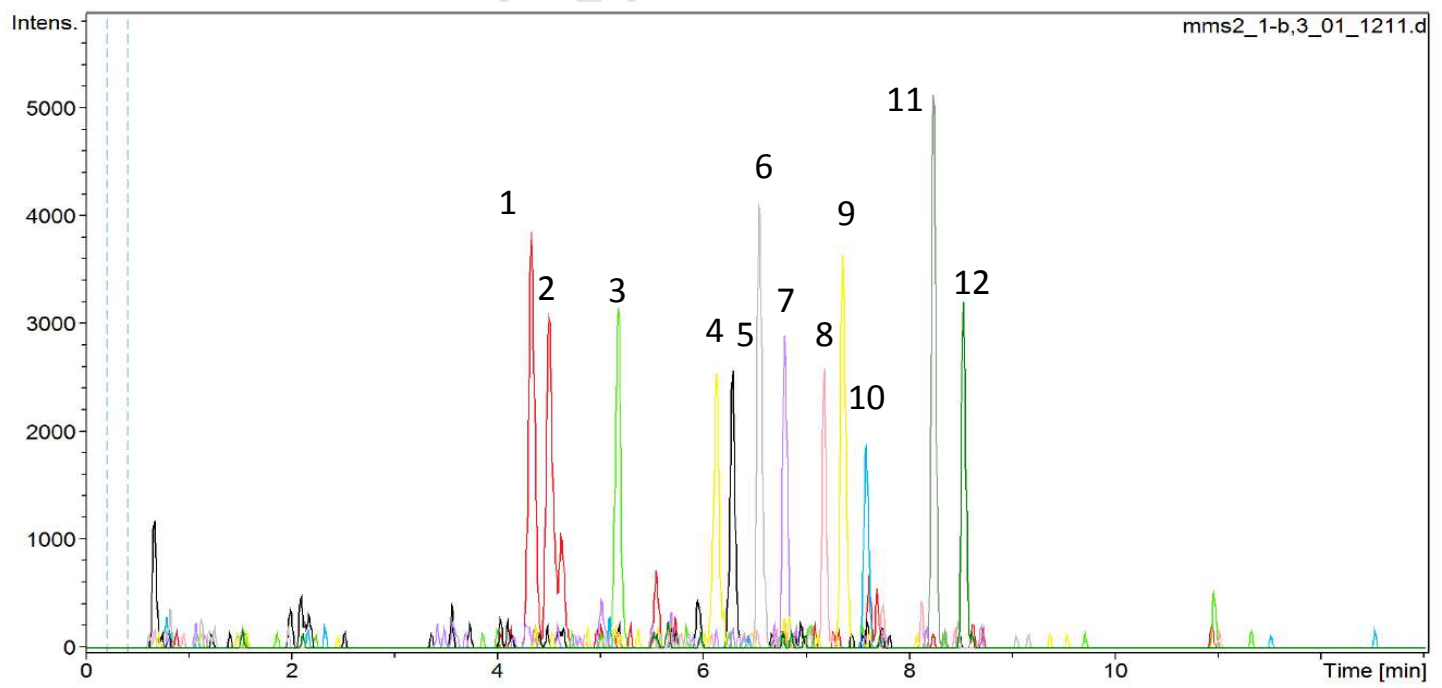


Figure 2.

(a)

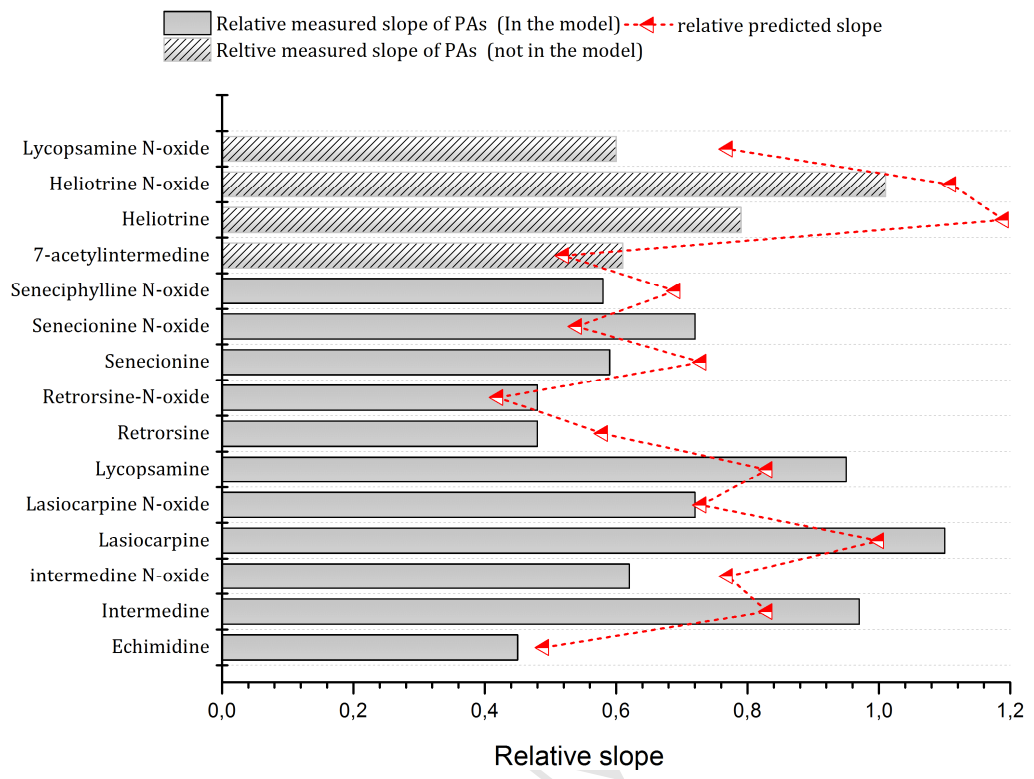

(b)
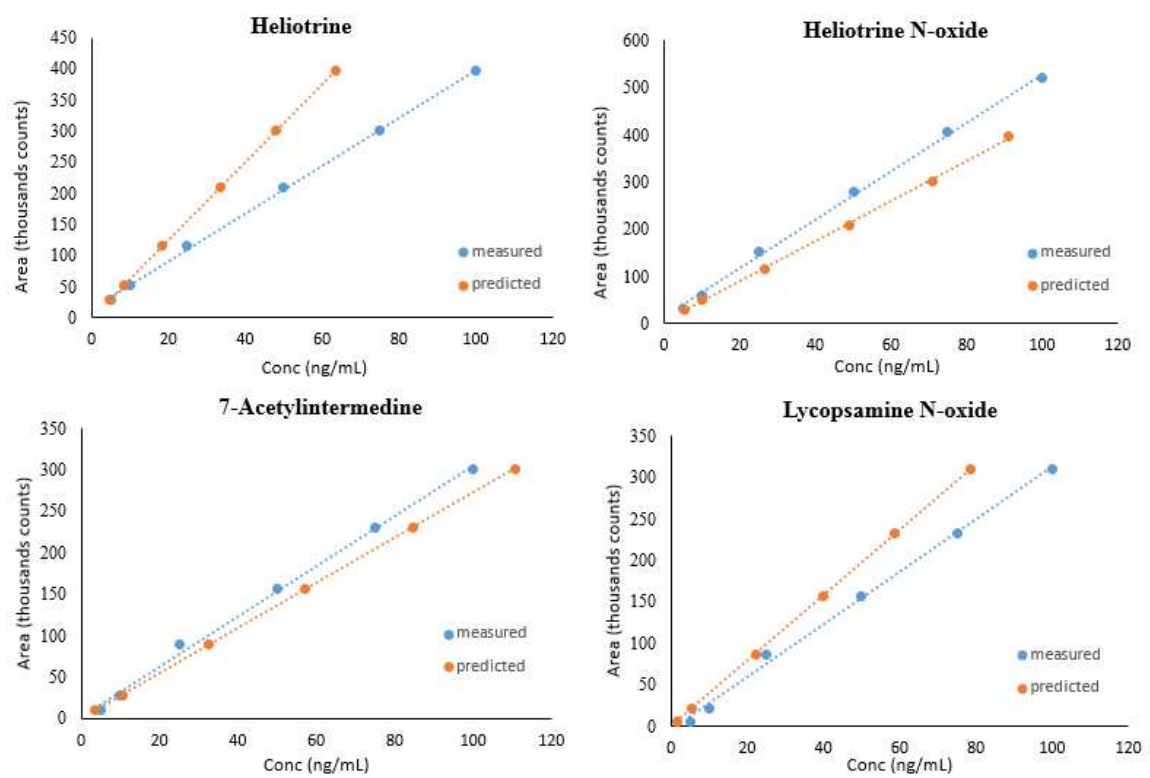
- Semi-quantification of other PAs by quantitative prediction model without standards

- Method validation for the analysis 12 PAs in honey

- Multi-target screening of potential PAs in honey samples

\section{GRAPHIC ABSTRACT}

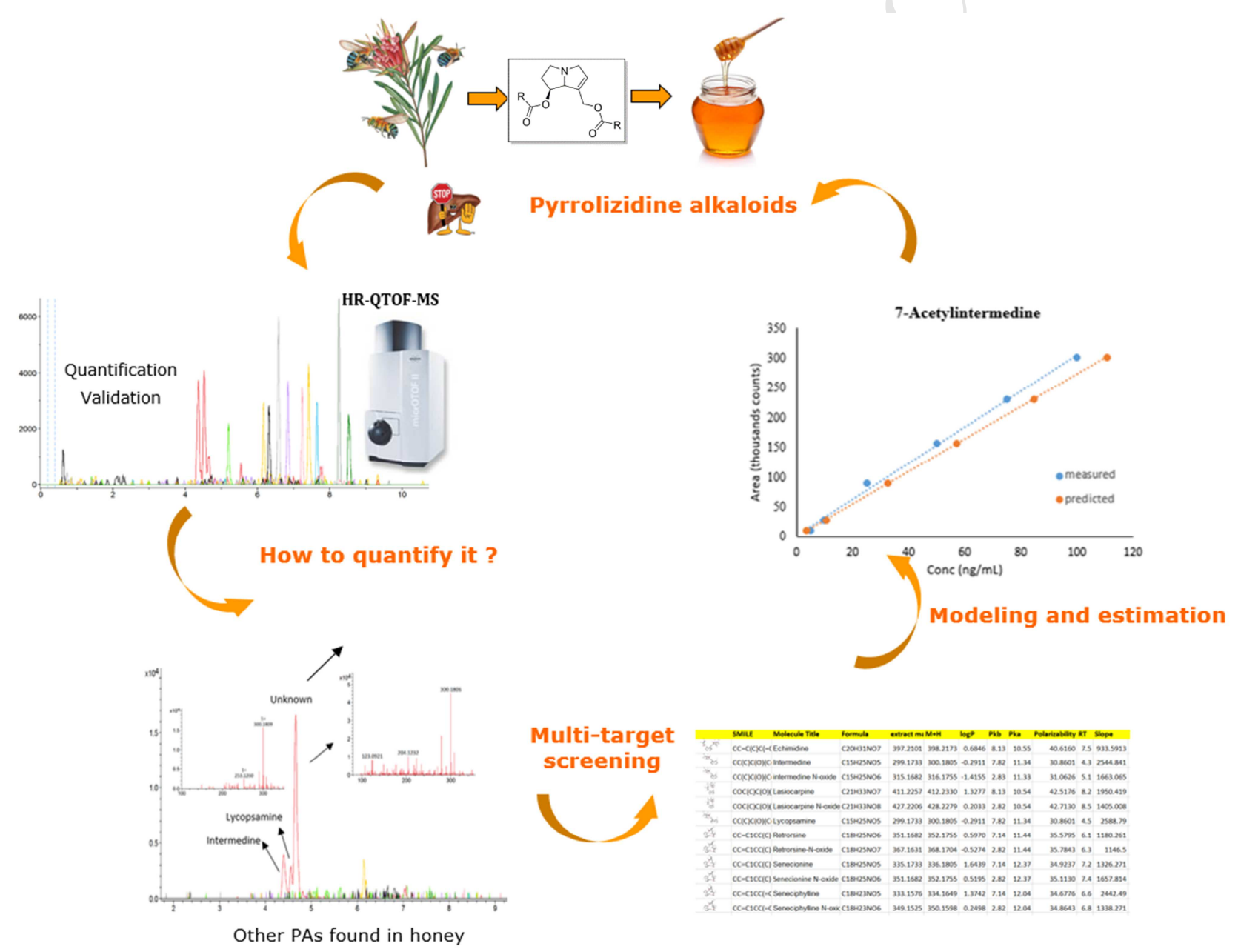

